\title{
RANCANG BANGUN ROBOT LENGAN PEMINDAH BARANG 3 DOF MENGGUNAKAN METODE INVERSE KINEMATICS BERBASIS ANDROID
}

\author{
Afrizal Septiano Arisandi ${ }^{1}$, Joko Subur ${ }^{2}$, Suryadhi ${ }^{3}$ \\ 1,2,3 Program Studi Teknik Elektro, Universitas Hang Tuah \\ ${ }^{1}$ afrizalseptiano@gmail.com \\ ${ }^{2}$ joko.subur@hangtuah.ac.id \\ ${ }^{3}$ suryadhi ehangtuah.ac.id
}

\begin{abstract}
Moving object process from one place to another is usually done with the conventional way using human power, then it can certainly to get heavy objects and the farther the distance of displacement, manpower required objects are also getting bigger. It is judged ineffective considering the limitations of human capability in the shift of weight and time limitations of humans in the work. The robot arm was designed to have 3 DOF (Degree of Freedom) and the whole joint is revolute and implemented using servo dynamixel $A X-12 A$. Input from this robot is initial coordinates and final coordinates are then computing by the method of inverse kinematics with an output in the form of large angle of each joint required in order for the robot arm reaches the point coordinates. Results from research that has been done, the robot is able to move the object from point coordinate to another within an average period of 6 to 7 seconds as well as the level error that occurred in the achievement of the desired angle of $0.64 \%$. 3DOF using inverse kinematics method is very effective in carrying out its functions to move an object.
\end{abstract}

Keywords-arm robot, inverse kinematics, servo dynamixel $A X$ 12A, Android.

Intisari-Proses perpindahan barang dari satu tempat ke tempat yang lain biasanya dilakukan dengan cara konvensional menggunakan tenaga manusia, maka dapat dipastikan semakin berat benda dan semakin jauh jarak perpindahan benda tenaga manusia yang dibutuhkan juga semakin besar. Hal ini dinilai kurang efektif mengingat keterbatasan kemampuan manusia dalam memindahkan barang berat dan keterbatasan waktu manusia dalam bekerja. Berdasarkan permasalahan tersebut diperlukan sebuah robot lengan yang mampu melakukan proses perpindahan barang dari tempat ke tempat lain. Robot lengan ini didesain memiliki 3 DOF (Degree of Freedom) servo dynamixel AX-12A. Input dari robot ini berupa koordinat awal dan koordinat akhir yang kemudian dikomputasikan dengan metode inverse kinematics dengan output berupa besar sudut yang dibutuhkan masing-masing joint agar robot lengan mencapai titik koordinat tersebut dan dikendalikan oleh aplikasi pada android melalui bluetooth. Hasil dari penelitian yang telah dilakukan, robot mampu memindahkan barang dari satu titik koordinat ke titik koordinat yang lain dalam kurun waktu rata-rata 8 sampai 9 detik serta tingkat error yang terjadi dalam pencapaian sudut yang diinginkan sebesar $1.98 \%$ dan dapat dikendalikan jarak jauh dengan maksimal jarak 5 meter. Berdasarkan hasil tersebut dinilai sistem implementasi robot lengan pemindah barang 3DOF dengan menggunakan metode inverse kinematics ini sangat efektif dalam menjalankan fungsinya memindahkan barang.
Kata Kunci-robot lengan, inverse kinematics, servo dynamixel AX-12A, Android.

\section{PENDAHULUAN}

Orang Robot manipulator lengan saat ini telah banyak diaplikasikan dalam dunia industri, seperti pada robot las (welding robot), robot pemegang (handling robot), robot pelubang/pemotong(punching robot), robot mesin perkakas (tools machine robot), dan lain sebagainya. Salah satu bentuk robot yang sering dipakai adalah bentuk robot lengan anthropomorphic. Bentuk robot lengan ini mempunyai keunggulan fleksibilitas daerah kerja dalam 3 dimensi ruang sehingga sangat cocok untuk diaplikasikan di sebagian besar robot industry. Didunia robot lengan berperan sebagai pengganti manusia, memindahkan barang secara otomatis dari satu tempat ketempat yang lain, dan robot pemindah barang mempunyai dua jenis yaitu statis dan dinamis, dimana robot pemindah barang jenis statis sifatnya diam ditempat dan hanya bisa memindahkan barang atau objek diarea yang dibatasi, sedangkan robot pemindah barang jenis dinamis sifatnya bisa bergerak dan bisa memindahkan barang diarea yang luas [1].

Pada Tahun 2013 Mahasiswa di Universitas Tanjungpura telah melakukan penelitian yang berkaitan dengan pembuatan lengan robot pemindah barang, Robot tersebut menggunakan metode perhitungan kinematic, sehingga pergerakan robot lengan dapat diprediksi, permasalahannya yaitu lengan robot tersebut hanya digunakan untuk simulai pengambilan barang tanpa menghitung kemampuan - kemampuan penggerak untuk mengangkat terhadap beban yang diterima [2].

Dan pada tahun 2019 telah dirancang lengan robot berbasis mikrokontroler arduino uno dengan 4 sudut. Pada penelitian tersebut Permasalahannya yaitu kekuatan maksimal lengan robot untuk mengangkat barang adalah 2,5 ons, dengan panjang lengan beban $230 \mathrm{~mm}$ dan lengan kuasa $60 \mathrm{~mm}$ pada sudut end efektor $39 \mathrm{~cm} \mathrm{[3].}$

Metode inverse kinematics merupakan metode pergerakan robot lengan dengan variabel yang diketahui adalah titik koordinat tujuan, sehingga dibutuhkan perubahan besar sudut pada masing-masing joint robot lengan agar robot lengan mampu mencapai titik tersebut [4]. 
Berdasarkan permasalahan tersebut diperlukan sebuah robot lengan yang mampu melakukan proses perpindahan barang dari satu tempat ke tempat lain sehingga diharapkan mampu mempermudah kegiatan pemindahan barang yang dilakukan serta meningkatkan tingkat efektifitas baik dalam hal waktu, tenaga maupun kualitas dari suatu kegiatan [5]. Robot ini akan bertugas melakukan proses perpindahan barang dari satu titik koordinat ke titik koordinat yang lain. Input dari robot ini berupa titik koordinat yang kemudian dikomputasikan dengan metode inverse kinematics dengan output berupa besar sudut yang dibutuhkan masing masing joint agar robot lengan mencapai titik koordinat tersebut. Rancang bangun robot ini menggunakan smartphone android melalui bluetooth berbasis mikrokontroller.

Diharapkan penelitian ini dapat menghasilkan lengan robot 3 DOF menggunakan smartphone android melalui bluetooth untuk memindahkan barang-barang berdasarkan batasan-batasan yang telah ditentukan, Untuk mendeteksi faktor yang mempengaruhi lengan robot pada metode inverse kinematics.

\section{LANDASAN TEORI}

\section{A. Lengan Robot}

Lengan robot atau banyak diaplikasikan di dalam dunia industri, terutama digunakan sebagai pemindah barang dengan berat barang berskala besar, pengendaliannya pun bisa berupa otomatis atau secara manual. Robot otomatis merupakan robot yang dapat bergerak sesuai dengan sistem geraknya tanpa harus ada campur tangan manusia sedangkan robot manual merupakan robot yang bergerak sesuai dengan sistem geraknya dengan bantuan operator sebagai pengendalinya [5].

\section{B. Metode Inverse Kinematics 3 DOF (Degree of Freedom) \\ Pada perancangan metode inverse kinematics} didapatkan rumus dari perancangan link dan joint robot. Perhitungan rumus bertujuan untuk mendapatkan nilai $\theta 1, \theta 2, \theta 3$. Sebelum mencari ketiga nilai $\theta$ diasumsikan telah memiliki nilai dari koordinat $(\mathrm{x}, \mathrm{y}, \mathrm{z})$ dan panjang link (L1, L2, L3). [2]

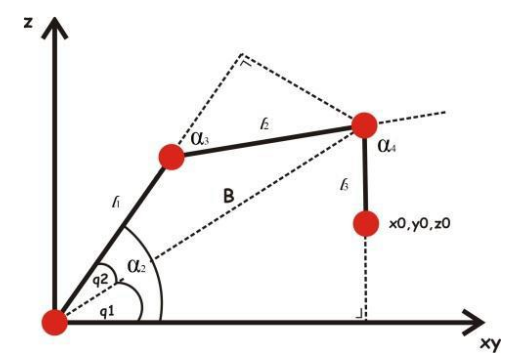

Gambar 1. Invers kinematika robot lengan
Rumus untuk mencari nilai $\theta 1$ dapat dilihat pada persamaan (1).

$\theta 1=\operatorname{atan} 2(y$,

Keterangan.

$\mathrm{x}=$ nilai koordinat $\mathrm{x}$

$\mathrm{y}=$ nilai koordinat $\mathrm{y}$

Pada persamaan (1) dengan input nilai koordinat $\mathrm{x}$ dan y maka akan didapatkan nilai dari $\theta 1$.

Setelah mencari nilai $\theta 1$ maka selanjutnya untuk mencari $\theta 2$ dan $\theta 3$ memerlukan nilai c3 dan s3. Nilai c3 dan s3 merupakan variabel bantu untuk menyelesaikan rumus $\theta 2$ dan $\theta 3$. Rumus untuk mencari nilai c3 dan s3 dapat dilihat pada persamaan (2) dan persamaan (3).

$$
\begin{aligned}
& c 3=\frac{\left(x^{2}+y^{2}+(z-L 1)^{2}-L^{2}-L 3^{2}\right)}{(2 x L 2 x L 3)} \\
& s 3=\sqrt{1-c 3^{2}}
\end{aligned}
$$

Keterangan.

$\mathrm{x}=$ nilai koordinat $\mathrm{x}$

$\mathrm{L} 1$ = panjang link pertama

$\mathrm{y}=$ nilai koordinat $\mathrm{y}$

L2 = panjang link kedua

$\mathrm{z}=$ nilai koordinat $\mathrm{z}$

L3 = panjang link ketiga

Kemudian selanjutnya adalah mencari nilai $\theta 3$ dengan rumus pada persamaan (4).

$\theta 3=\operatorname{atan} 2(s 3, c 3)$

Pada persamaan (4) dengan memasukan nilai dari variable s3 dan c3 maka akan didapatkan nilai $\theta 3$.

Setelah menemukan nilai $\theta 3$ selanjutnya mencari nilai dari $\theta 2$ dengan rumus pada persamaan (5).

$\theta 2=\operatorname{atan} 2((L 3 \times s 3),(L 2+(L 3 \times c 3)))$ 


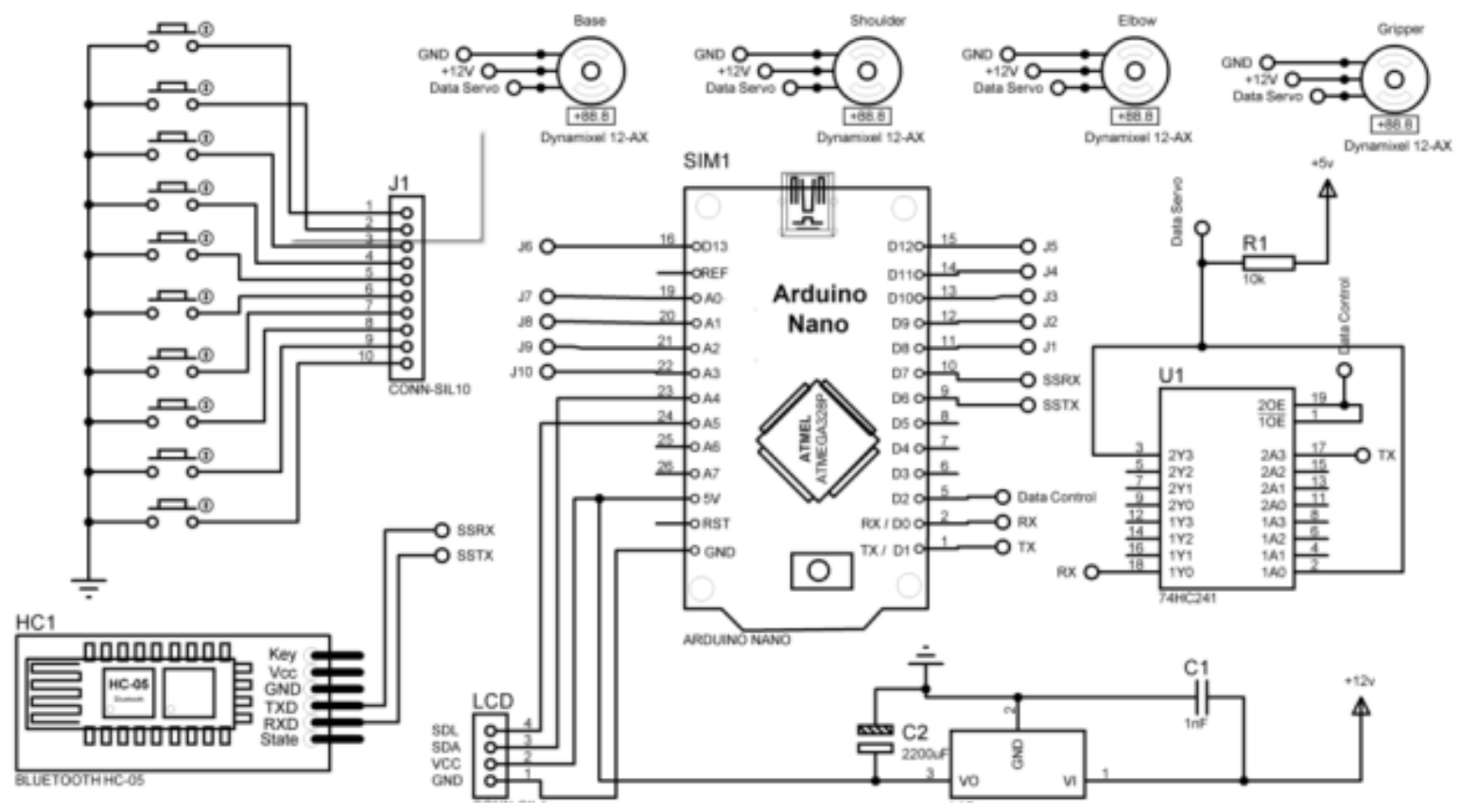

Gambar 2. Perancangan rangkaian hardware pada robot.

Keterangan.

L2 = panjang link kedua

L3 = panjang link ketiga

Pada persamaan 5 dengan memasukan nilai L2, L3, c3 dan s3 maka akan didapatkan nilai $\theta 2$.

\section{MIT App Inventor}

App Inventor adalah sistem perangkat lunak untuk membuat aplikasi pada perangkat Android. Uniknya, App Inventor dibuat tidak seperti sistem pengembangan aplikasi biasa, di mana seorang programmer harus menuliskan baris-baris kode program, melainkan dengan interaksi visual berbasis grafis Dalam hal ini, App Inventor dapat disebut sebagai sistem terpadu untuk mengembangkan aplikasi berbasis blog-blog grafis (dalam istilah asing: blocks language). Jika kita mengenal Scartch (http://scratch.mit.edu), App Inventor bekerja dengan cara yang kurang-lebih sama, tetapi untuk platform.

Perangkat bergerak pada yang berbasis Android [6]. Istilah App Inventor dan inventor digunakan sebagi sinonim. Inventor diuji coba pertama kali pada kalangangan terbatas juli 2010, kemudian dirilis ke publik pada desember tahun yang sama. Pengembangan Inventor dimotifikasi oleh keyakinan dan perspektif edukasi yang kuat bahwa pembelajaran aktif pemograman (secara visual) dapat menjadi wahana untuk memicu ide-ide baru dan kreatif [6].

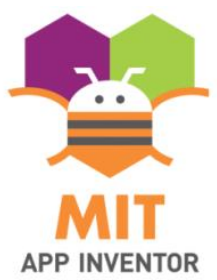

Gambar 3. Software MIT APP Inventor

\section{METODE PENELITIAN}

\section{A. Perancangan Sistem Robot}

Perancangan rangkaian hardware pada robot lengan dapat dilihat pada Gambar 2 yang terdiri dari beberapa bagian penyusun. Yaitu komponen masukan, komponen pengendali dan komponen keluaran. Perangkat masukan berupa Arduino dan kontroler berupa Smartphone Melalui Komunikasi Bluetooth, kemudian komponen pengendali adalah IC 74HC241, sedangkan untuk komponen keluaran adalah motor servo. Smartphone berfungsi sebagai masukan ke arduino yang nantinya akan dilanjutkan ke IC 74HC241 dan dilanjutkan ke motor servo dalam bentuk gerakan.

Tabel I

Konfigurasi pin Arduino dan IC74LS241N

\begin{tabular}{|l|l|}
\hline Arduino & \multicolumn{1}{|c|}{ IC 74LS241N } \\
\hline Pin 0 (Rx) & Pin 18 \\
\hline Pin 1 (Tx) & Pin 17 \\
\hline Pin 2 & Pin 1, Pin 19 \\
\hline GND & Pin 10 \\
\hline
\end{tabular}

Pada Tabel I adalah penyambungan antara pin pada Arduino dan kaki IC 74LS241N. Dapat dilihat Pin 0 (Rx) dan Pin 1 (Tx) pada Arduino disambungkan ke Pin 18 dan Pin 17 pada kaki IC. Kemudian Pin 2 sebagai Data kontrol pada Arduino disambungkan ke Pin 1 dan Pin 19 pada kaki IC. Dan yang terakhir adalah GND pada Arduino disambungkan ke Pin 10 pada kaki IC.

\section{B. Perancangan Desain Link dan Joint}

Tinggi dari dasar base ke joint 2 yaitu $8 \mathrm{~cm}$ dan lebar base yaitu $15 \mathrm{~cm}$, link 1 sebagai Shoulder yaitu $20 \mathrm{~cm}$ dan link 2 sebagai Elbow yaitu $25 \mathrm{~cm}$ dan panjang endeffector yaitu $7 \mathrm{~cm}$. jadi, total tinggi robot lengan ini adalah $52 \mathrm{~cm}$ dan lebar masing -masing link yaitu $3.2 \mathrm{~cm}$. Robot lengan memiliki 3 (tiga) DOF (derajat kebebasan) 
dan tersusun atas lima buah servo yang sama. Yakni 4 buah servo dengan torsi $15 \mathrm{~kg}$ (Dynamixel AX-12A). Dimensi robot ditunjukan pada Gambar 4.

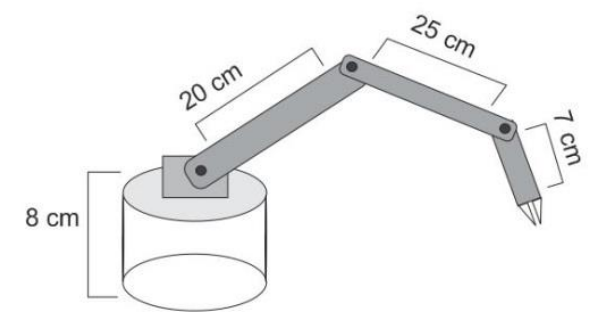

Gambar 4. Dimensi robot lengan 3 DoF

\section{Flowchart Sistem Kerja Alat}

Adapun diagram alur program yang akan digunakan pada penelitian ini adalah sebagai berikut.

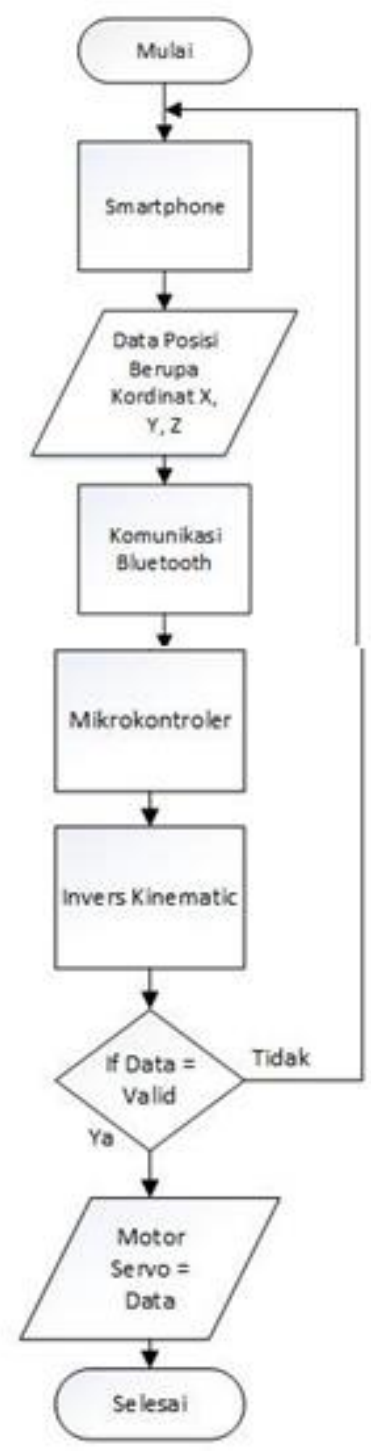

Gambar 5. Flowchart Sistem Pemetaan Ruangan

Diagram ini merupakan gambaran umum dimana robot dapat dikendalikan menggunakan komputer berdasarkan perhitungan dan simulasi dengan mengirimkan data ke sistem minimum mikrokontroler menggunakan jalur komunikasi serial. Jalur serial ini nantinya diakses oleh mikrokontroler sebagai data untuk menginstruksikan pergerakan motor servo.

\section{Perancangan Perangkat Lunak Sederhana}

Untuk menggerakan servo pada alat dibutuhkan software yang diprogramkan ke mikrokontroler melalui komunikasi bluetooth, dengan menggunakan program pihak ketiga dengan MIT App Inverter.

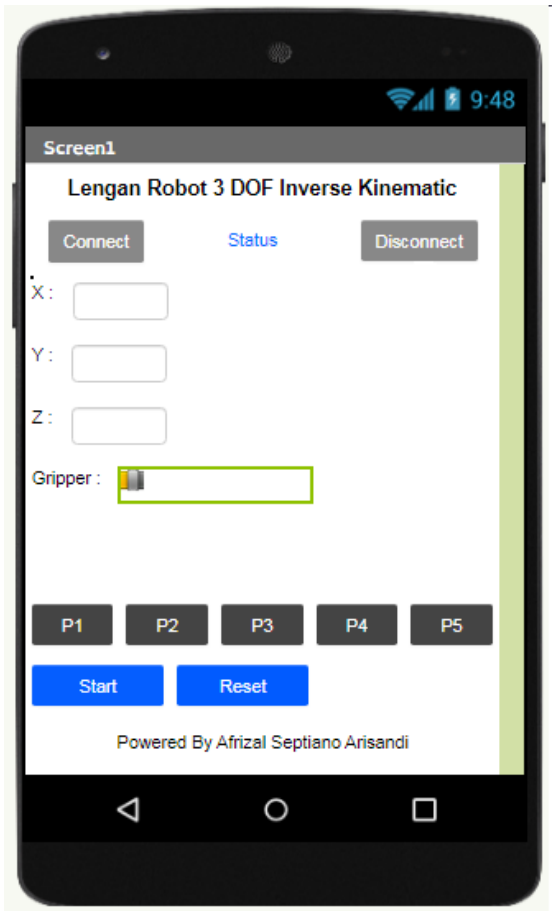

Gambar 6. Tampilan program menggerakan servo dengan software MIT APP Inverter.

Program tersebut dibuat menggunakan MIT App Inverter dan bekerja sesuai dengan flowchart pada Gambar 5. dengan cara mengkoneksikan smartphone ke mikrokontroller menggunakan komunikasi Bluetooth dan memberi nilai / input sesuai tampilan Gambar 6. dan tombol P1 sampai P5 berfungsi untuk menyimpan tiap posisi dan tombol start digunakan untuk memulai program yang sudah disimpan, dan tombol reset berfungsi sebagai menghilangkan program yang sebelumnya disimpan.

\section{HASIL DAN PEMBAHASAN}

Pada penelitian ini dilakukan 3 pengujian yaitu waktu yang dibutuhkan oleh robot untuk mencapai titik koordinat yang telah ditentukan, ketepatan putaran sudut servo yang dihasilkan dari perhitungan rumus yang dilakukan oleh sistem dan ketepatan sudut yang mampu dicapai oleh robot melalu perbandingan metode inverse kinematics.

Pengujian waktu pencapaian koordinat ini bertujuan untuk mengetahui kecepatan gerak robot dalam mencapai titik koordinat yang telah ditentukan. Proses pengukuran waktu akan dilakukan dengan menggunakan timer sebagai alat pengukur waktu dengan mengambil 5 jenis motion yang berbeda. Titik koordinat awal dibuat sama sebagai acuan letak pengambilan barang. Pada tiap motion akan 
dilakukan percobaan sebanyak 10 kali yang nantinya dirata-rata untuk mengetahui waktu yang dibutuhkan pada setiap motion. Hasil dari pengujian waktu pencapaian titik koordinat dapat dilihat pada Tabel II.

Tabel II

Hasil Pengujian Waktu Pencapaian Titik Koordinat

\begin{tabular}{|c|c|c|}
\hline Motion & Koordinat & $\begin{array}{c}\text { Rata-rata } \\
\text { Waktu(s) }\end{array}$ \\
\hline 1 & $(0,26,28) \mathrm{ke}(17,26,25)$ & 8,6843 \\
\hline 2 & $(0,26,28) \mathrm{ke}(0,0,10)$ & 9,1157 \\
\hline 3 & $(0,26,28) \mathrm{ke}(0,25,15)$ & 8,7397 \\
\hline 4 & $(0,26,28) \mathrm{ke}(-15,26,4)$ & 8,9762 \\
\hline 5 & $(0,26,28) \mathrm{ke}(-34,0,32)$ & 9,0387 \\
\hline
\end{tabular}

Hasil dari pengujian menunjukkan kelima motion mendapatkan waktu rata-rata yang hampir sama sekitar 8 sampai 9 detik walaupun dengan jarak yang berbeda. Dari hal ini dapat diketahui bahwa rata rata waktu robot memindahkan barang sekitar 8 sampai 9 detik.

\section{A. Pengujian Ketepatan Sudut Putar Servo}

Pengujian ketepatan sudut putar motor servo bertujuan untuk mengetahui akurasi gerak berupa sudut yang dihasilkan motor servo. Proses pengujian ketepatan putaran motor servo ini dilakukan dengan membandingkan hasil dari dua cara pengukuran yaitu pengukuran secara manual menggunakan busur derajat dan pengukura rumus inverse kinematics secara sistem pada arduino uno. Hasil pengujian ketepatan sudut putar pada servo 1 , servo 2 , dan servo 3 dapat dilihat pada Tabel III, Tabel IV, dan Tabel V.

Tabel III

Hasil Pengujian Ketepatan Sudut Putar Servo 1

\begin{tabular}{|c|c|c|c|c|}
\hline Koordinat & $\begin{array}{c}\text { Sudut } \\
\text { Teta1 }\end{array}$ & $\begin{array}{c}\text { Sudut } \\
\text { yang } \\
\text { terukur }\end{array}$ & Selisih & Error \\
\hline$-27,16,6$ & 149 & 151.94 & 2.94 & 1.97 \\
\hline$-26,17,6$ & 147 & 147.01 & 0.01 & 0.01 \\
\hline$-14,25,7$ & 120 & 120.65 & 0.65 & 0.54 \\
\hline$-10,10,13$ & 135 & 134.47 & 0.53 & 0.39 \\
\hline$-9,15,10$ & 121 & 118.36 & 2.64 & 2.18 \\
\hline $0,24,10$ & 90 & 89.76 & 0.24 & 0.27 \\
\hline $17,17,8$ & 45 & 45.88 & 0.88 & 1.96 \\
\hline $24,24,6$ & 45 & 46.32 & 1.32 & 2.93 \\
\hline $26,18,6$ & 35 & 36.51 & 1.51 & 4.31 \\
\hline $28,31,13$ & 48 & 49.4 & 1.4 & 2.92 \\
\hline
\end{tabular}

Tabel IV

Hasil Pengujian Ketepatan Sudut Putar Servo 2

\begin{tabular}{|c|c|c|c|c|}
\hline Koordinat & $\begin{array}{c}\text { Sudut } \\
\text { Teta2 }\end{array}$ & $\begin{array}{c}\text { Sudut } \\
\text { yang } \\
\text { terukut }\end{array}$ & Selisih & Error \\
\hline$-27,16,6$ & 48 & 49.13 & 1.13 & 2.35 \\
\hline$-26,17,6$ & 49 & 46.83 & 2.17 & 4.43 \\
\hline$-14,25,7$ & 55 & 55.92 & 0.92 & 1.67 \\
\hline$-10,10,13$ & 85 & 81.72 & 3.28 & 3.86 \\
\hline$-9,15,10$ & 81 & 77.81 & 3.19 & 3.94 \\
\hline $0,24,10$ & 65 & 64.99 & 0.01 & 0.02 \\
\hline $17,17,8$ & 66 & 68.45 & 2.45 & 3.71 \\
\hline
\end{tabular}

\begin{tabular}{|c|c|c|c|c|}
\hline Koordinat & $\begin{array}{c}\text { Sudut } \\
\text { Teta2 }\end{array}$ & $\begin{array}{c}\text { Sudut } \\
\text { yang } \\
\text { terukut }\end{array}$ & Selisih & Error \\
\hline $24,24,6$ & 40 & 40.48 & 0.48 & 1.2 \\
\hline $26,18,6$ & 47 & 46.89 & 0.11 & 0.23 \\
\hline $28,31,13$ & 20 & 20 & 0 & 0 \\
\hline
\end{tabular}

Tabel V

Hasil Pengujian Ketepatan Sudut Putar Servo 3

\begin{tabular}{|c|c|c|c|c|}
\hline Koordinat & $\begin{array}{c}\text { Sudut } \\
\text { Teta3 }\end{array}$ & $\begin{array}{c}\text { Sudut } \\
\text { yang } \\
\text { terukur }\end{array}$ & Selisih & Error \\
\hline$-27,16,6$ & 80 & 82.64 & 2.64 & 3.3 \\
\hline$-26,17,6$ & 82 & 79 & 3 & 3.66 \\
\hline$-14,25,7$ & 91 & 93.12 & 2.12 & 2.33 \\
\hline$-10,10,13$ & 132 & 127.97 & 4.03 & 3.05 \\
\hline$-9,15,10$ & 127 & 123.33 & 3.67 & 2.89 \\
\hline $0,24,10$ & 106 & 106.41 & 0.41 & 0.39 \\
\hline $17,17,8$ & 108 & 111.21 & 3.21 & 2.97 \\
\hline $24,24,6$ & 68 & 68.61 & 0.61 & 0.9 \\
\hline $26,18,6$ & 80 & 79.09 & 0.91 & 1.14 \\
\hline $28,31,13$ & 0 & 0 & 0 & 0 \\
\hline
\end{tabular}

Dari hasil dari kedua tabel dapat ditentukan rata-rata dari persentase error servo 1, servo 2, dan servo 3 dengan menjumlahkan seluruh data persentase error dibagi banyaknya percobaan sehingga mendapatkan persentase sebesar $1.98 \%$. Perlu diketahui bahwa selisih yang dihasilkan dengan busur derajat terjadi karena akurasi dari busur derajat sebesar 3 derajat.

\section{B. Pengujian Kerja Robot Lengan 3 Dof}

Pada tahapan ini, robot lengan ditugaskan untuk menuju koordinat yang diinginkan titik yang berbeda untuk dipindahkan ke tempat pengumpulan objek (home). Penugasan yang pertama adalah ditentukan posisi awal yang diinginkan, misalkan pada posisi $(17,0,4)$ kemudian klik tombol "OK". Setelah itu, ditentukan posisi koordinat pertama dan koordinat kedua, misalkan pada posisi $(17,30,25)$ dan $(-15,26,4)$. Jika robot ingin diperintahkan menuju koordinat 1, input koordinat pertama dan klik "OK", maka robot akan menuju koordinat pertama. Begitu pula untuk menuju koordinat kedua.

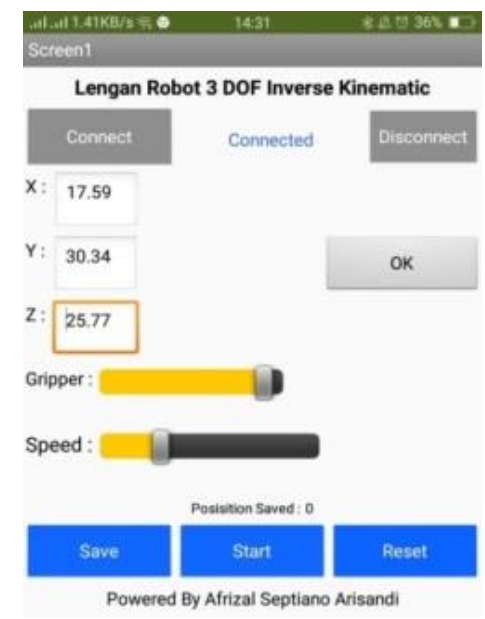

Gambar 7. Software pada Robot 


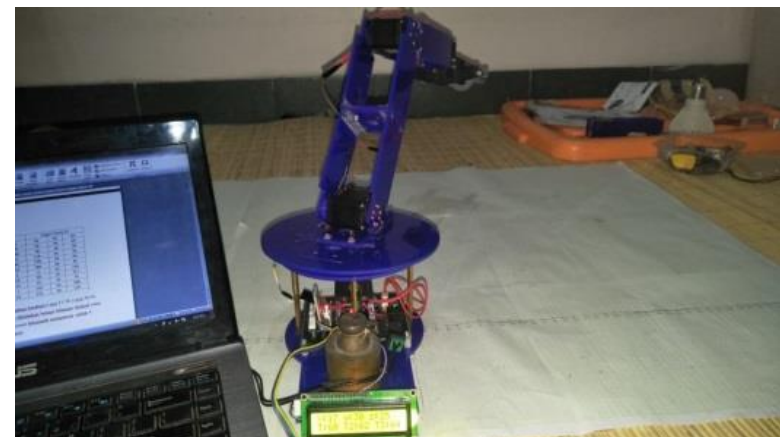

Gambar 8. Lengan robot berada dikoordinat pertama

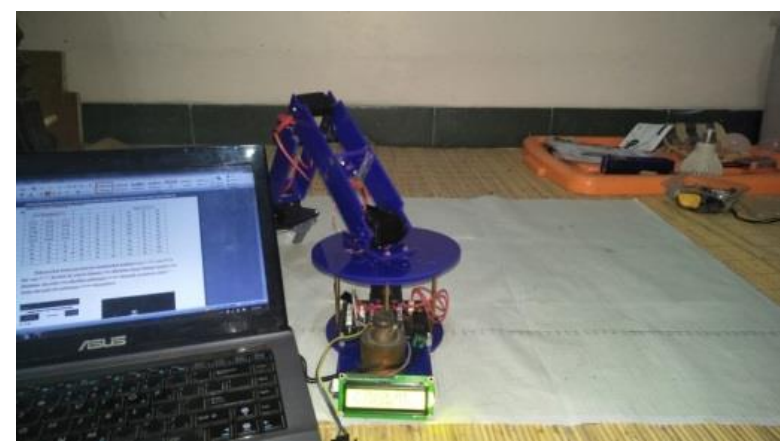

Gambar 9. Lengan robot berada dikoordinat kedua

C. Pengujian Kekuatan Lengan Robot Memindahkan

Botol

Pada percobaan ketujuh dilakukan pengujian ketahanan lengan robot pada saat memindahkan botol, pada percobaan kali ini berat botol yang dipindahkan dibagi menjadi 3, dan setiap jenis berat botol dilakukan 15 kali percobaan.

Tabel VI

Pengujian ketahanan lengan robot pada botol kosong

\begin{tabular}{|c|c|c|c|}
\hline NO & $\begin{array}{c}\text { Total } \\
\text { Pecobaan }\end{array}$ & Keberhasilan & Kegagalan \\
\hline 1 & 5 & 5 & 0 \\
\hline 2 & 10 & 15 & 0 \\
\hline 3 & 15 & 30 & 0 \\
\hline Total & 30 & 30 & 0 \\
\hline
\end{tabular}

Berdasarkan hasil dari 30 kali percobaan pada ke 3 botol berat 10 gram, maka disajikandata total keberhasilan ketahanan lengan robot dan total kegagalan ketahanan lengan robot seperti yang disajikan pada Tabel VI yang menunjukan bahwa total keberhasilan ketahanan lengan robot sebesar 30 dan total kegagalan sebesar 0 dari 30 percobaan. Dari data tersebut dapat dicari persentase tingkat keberhasilan sebagai berikut.

Tingkat Keberhasilan $=\frac{\text { Total Keberhasilan }}{\text { Total Percobaan }} x 100 \%$

Tingkat Keberhasitan $=\frac{30}{30} \times 100 \%$

Tingkat Reberhasilan $=100 \%$

Dari persamaan (6) menunjukan bahwa tingkat keberhasilan robot dalam ketahanan mengangkat botol sebesar $100 \%$ dikarenakan botol beratnya 10 gram dan tidak ada beban.
Tabel VII

Pengujian ketahanan lengan robot pada botol dengan berat 35 gram

\begin{tabular}{|c|c|c|c|}
\hline NO & $\begin{array}{c}\text { Total } \\
\text { Pecobaan }\end{array}$ & Keberhasilan & Kegagalan \\
\hline 1 & 5 & 5 & 0 \\
\hline 2 & 10 & 15 & 0 \\
\hline 3 & 15 & 30 & 0 \\
\hline Total & 30 & 30 & 0 \\
\hline
\end{tabular}

Berdasarkan hasil dari 30 kali percobaan pada ke 3 botol berat 35 gram, maka disajikandata total keberhasilan ketahanan lengan robot dan total kegagalan ketahanan lengan robot seperti yang disajikan pada Tabel VII yang menunjukan bahwa total keberhasilan ketahanan lengan robot sebesar 27 dan total kegagalan sebesar 3 dari 30 percobaan. Dari data tersebut dapat dicari persentase tingkat keberhasilan sebagai berikut.

Tingkat Keberhasilan $=\frac{\text { Total Keberhasitan }}{\text { Total Percobaan }} x 100 \%$

Tingkat Keberhasitan $=\frac{27}{30} \times 100 \%$

Tingkat Keberhasitan $=90 \%$

Dari persamaan (7) menunjukan bahwa tingkat keberhasilan robot dalam ketahanan mengangkat botol sebesar 90\%. Hal yang mempengaruhi tingkat keberhasilan ketahanan lengan robot tidak dapat 100\% kemungkinan disebabkan oleh beberapa faktor, yaitu kemungkinan motor servo pada lengan robot sudah tidak kuat menahan beban dari botol, dan motor servo pada bagian gripper juga tidak kuat menahan beban dari botol tersebut dan akhirnya motor servo terjadi overload dan overheating (kondisi motor servo panas karena terlalu lama menahan lengan dan beban).

Tabel VIII

Pengujian ketahanan lengan robot pada botol dengan berat 70 gram

\begin{tabular}{|c|c|c|c|}
\hline NO & $\begin{array}{c}\text { Total } \\
\text { Pecobaan }\end{array}$ & Keberhasilan & Kegagalan \\
\hline 1 & 5 & 5 & 0 \\
\hline 2 & 10 & 15 & 0 \\
\hline 3 & 15 & 30 & 0 \\
\hline Total & 30 & 30 & 0 \\
\hline
\end{tabular}

Berdasarkan hasil dari 30 kali percobaan pada ke 3 botol berat 70 gram, maka disajikandata total keberhasilan ketahanan lengan robot dan total kegagalan ketahanan lengan robot seperti yang disajikan pada Tabel VIII yang menunjukan bahwa total keberhasilan ketahanan lengan robot sebesar 22 dan total kegagalan sebesar 8 dari 30 percobaan. Dari data tersebut dapat dicari persentase tingkat keberhasilan sebagai berikut.

$$
\begin{aligned}
& \text { Tingkat } \text { Reberhasilan }=\frac{\text { Total Keberhasilan }}{\text { Total Pencobaan } x 100 \%} \\
& \text { Tingkat } \text { Reberhasilan }=\frac{22}{30} x 100 \% \\
& \text { Tingkat } \text { Reberhasitan }=73 \%
\end{aligned}
$$


Dari persamaan (8) menunjukan bahwa tingkat keberhasilan robot dalam ketahanan mengangkat botol sebesar 73\%. Hal yang mempengaruhi tingkat keberhasilan ketahanan lengan robot tidak dapat $100 \%$ kemungkinan disebabkan oleh beberapa faktor, yaitu kemungkinan motor servo pada lengan robot sudah tidak kuat menahan beban dari botol, dan motor servo pada bagian gripper juga tidak kuat menahan beban dari botol dan akhirnya motor servo terjadi overload dan overheating (kondisi motor servo panas karena terlalu lama menahan lengan dan beban), semakin berat beban yang diberikan maka motor servo menjadi panas dan motor servo berhenti paksa dengan sendirinya

\section{KESIMPULAN}

Dari hasil tahapan perancangan, implementasi dan analisis hasil pengujian yang dilakukan maka dapat dibuat kesimpulan pada perancangan metode inverse kinematics robot lengan untuk proses pemindahan barang dilakukan secara matematis menggunakan fungsi trigonometri. Dari hasil perhitungan matematis kemudian di implementasikan dalam bentuk kode pemrograman pada Arduino, dari hasil pengujian waktu pencapaian titik koordinat dapat dianalisis untuk memindahkan barang pada kelima motion memiliki waktu rata-rata selama 8 - 9 detik, hasil pengujian ketepatan sudut motor servo yang dilakukan sebanyak 10 kali pada 3 buah masing-masing motor servo didapatkan rata-rata persentase error sebesar $1.98 \%$, dari hasil 30 pengujian ketahanan robot lengan hanya mampu mengangkat beban 70 gram.

\section{UCAPAN TERIMA KASIH}

Mengucap terimakasih kepada Program Studi Teknik Elektro Universitas Hang Tuah yang telah memfalisitasi pengerjaan penelitian di workshop robotika.

\section{REFERENSI}

[1] M. I. Afandi, "Simulasi Pergerakan Trajectory Planning Pada Robot Lengan Anthropomorphic", Puslit KIM-LIP, Tangerang, 2009.

[2] U. Ristian, F. Hadary, and Y. Brianorman, "Visualisasi Dan Pengendalian Gerak Robot Lengan 4 DOF menggunakan Visual Basic Jurusan Sistem Komputer", Fakultas MIPA Universitas Tangjungpura, 2013.

[3] Syakranullah, "Rancang Bangun Robot Lengan Berbasis Mikrokontroler Arduino Uno", Prodi Sarjana Teknologi Rekayasa Manufaktur, 2019.

[4] Setiawan and Eko, "Robotics lecture nodes (Indonesia version). Faculty of computer science and engineering", Malang: Brawijaya University, 2015.

[5] Tri, Gita and Setiawan, "Robot Lengan Pemindah Barang Berdasarkan Ukurannya Berbasis Mikrokontroler", Eprints Journal., vol 5 no. 2, pp. 1 - 5, 2014Available: http://eprints.mdp.ac.id/1190/

[6] A. D. Rumate, X. Najoan, and B. A. Sugiarso, "Rancang Bangun Aplikasi Berbasis Android Untuk Informasi Kegiatan dan Pelayanan Gereja," EJournal Teknik Elektro dan Komputer., Vol. 6, no.1,
2017.

[7] Bahri. "Sistem Kontrol Penerangan Menggunakan Arduino Uno Pada Universitas Ichsan Gorontalo", Universitas Ichsan Gorontalo. Vol.09. No.03, 2017.

[8] Dina Caysar. "Pengaturan Pergerakan Robot Lengan Smart Arm Robotic Ax-12a Melalui Pendekatan Geometry Based Kinematic Menggunakan Arduino". Jurusan Teknik Elektro Fakultas Teknik Universitas Brawijaya. 2014.

[9] Istiqlal F., Rizal M., Wijaya K. "Implementasi Sensor Warna Pada Robot Lengan Pemindah Barang Menggunakan Inverse Kinematic”, Program Studi Teknik Informatika, Fakultas Ilmu Komputer, Universitas Brawijaya. 2019.

[10] Pitowarno, Endro. "Robotika, Desain, Kontrol, dan Kecerdasan" Buatan. Penerbit Andi: Yogyakarta. 2006. 